\title{
Streptozotocin-induced mechanical hypernociception is not dependent on hyperglycemia
}

\author{
J.M. Cunha' ${ }^{1}$, M.I. Funez ${ }^{1}$, F.Q. Cunha' ${ }^{1}$, C.A. Parada² and S.H. Ferreira ${ }^{1}$ \\ ${ }^{1}$ Departamento de Farmacologia, Faculdade de Medicina de Ribeirão Preto, Universidade de São Paulo, \\ Ribeirão Preto, SP, Brasil \\ ${ }^{2}$ Instituto de Biologia, Universidade Estadual de Campinas, Campinas, SP, Brasil \\ Correspondence to: J.M. Cunha, Departamento de Psicologia e Educação, FFCLRP, USP, \\ Av. Bandeirantes, 3900, 14049-900 Ribeirão Preto, SP, Brasil \\ Fax: +55-16-3633-0619. E-mail: joicecunha@hotmail.com
}

\begin{abstract}
Since streptozotocin (STZ)-induced diabetes is a widely used model of painful diabetic neuropathy, the aim of the present study was to design a rational protocol to investigate whether the development of mechanical hypernociception induced by STZ depends exclusively on hyperglycemia. Male Wistar rats (180-200 g; N =6-7 per group) received a single intravenous injection of STZ at three different doses $(10,20$, or $40 \mathrm{mg} / \mathrm{kg})$. Only the higher dose $(40 \mathrm{mg} / \mathrm{kg})$ induced a significant increase in blood glucose levels, glucose tolerance and deficiency in weight gain. However, all STZ-treated rats (hyperglycemic or not) developed persistent (for at least 20 days) and indistinguishable bilateral mechanical hypernociception that was not prevented by daily insulin treatment (2 IU twice a day, sc). Systemic morphine $(2 \mathrm{mg} / \mathrm{kg}$ ) but not local (intraplantar) morphine treatment ( $8 \mu \mathrm{g} / \mathrm{paw})$ significantly inhibited the mechanical hypernociception induced by STZ (10 or $40 \mathrm{mg} / \mathrm{kg}$ ). In addition, intraplantar injection of STZ at doses that did not cause hyperglycemia (30, 100 or $300 \mu \mathrm{g} / \mathrm{paw})$ induced ipsilateral mechanical hypernociception for at least $8 \mathrm{~h}$ that was inhibited by local and systemic morphine treatment $(8 \mu \mathrm{g} / \mathrm{paw}$ or $2 \mathrm{mg} / \mathrm{kg}$, respectively), but not by dexamethasone $(1 \mathrm{mg} / \mathrm{kg}, \mathrm{sc})$. The results of this study demonstrate that systemic administration of STZ induces mechanical hypernociception that does not depend on hyperglycemia and intraplantar STZ induces mechanical sensitization of primary sensory neurons responsive to local morphine treatment.
\end{abstract}

Key words: Streptozotocin; Mechanical hyperalgesia; Hyperglycemia; Insulin and glucose tolerance test

Research supported by FAPESP (\#2000/10258-5; \#01/07838-2), CNPq (\#314/7), and Programa de Núcleos de Excelência (PRONEX), Brazil. J.M. Cunha was the recipient of a FAPESP Doctorate fellowship (\#2000/10258-5).

Received September 26, 2007. Accepted December 8, 2008

\section{Introduction}

Neuropathy is the most common chronic complication of diabetes mellitus. The prevalence of diabetic peripheral neuropathy is about $32 \%$ in both type 1 and type 2 diabetic subjects (1). One of the most elusive symptoms in diabetic neuropathy is pain, characterized by mechanical and thermal hyperalgesia (an increased response to a stimulus, which is normally painful) or allodynia (pain due to a stimulus that does not normally provoke pain), phenomena that involve two components, i.e., nociception and perception. Since animal models do not allow discrimination of the emotional component, the terms nociception and hypernociception are used to describe overt behavior induced by mechanical stimulation and increased nociceptor sensitivity, respectively (2). The pathophysiology of painful diabetes neuropathy is unclear, although it has been associated with impaired peripheral nerve conduction and degeneration of myelinated and unmyelinated fibers (3).

To provide information on underlying mechanisms and to evaluate potential therapies, experimental research on diabetic neuropathy is usually carried out using genetic or chemically induced diabetic animal models (4). Streptozotocin (STZ), an antibiotic extracted from Streptomyces 
achromogenes, is one of the chemical agents most commonly used to induce experimental diabetic syndrome in mammals. It has been well defined that a systemic injection of STZ induces hyperalgesia to thermal (5-9), mechanical (8-15) and chemical $(8,11,16-18)$ noxious stimuli. STZinduced hyperalgesia is frequently associated with hyperglycemia because in some studies its development was prevented by insulin treatment $(6,7,12,14,19,20)$. Although these studies suggest that STZ induces painful diabetic neuropathy, it is important to point out that the majority of studies evaluating STZ-induced hyperalgesia only include animals rendered hyperglycemic. In fact, it was observed that, in vivo, chronic perfusion of hyperglycemic solution into the dorsal root ganglion or into a segment of the sciatic nerve induces mechanical hyperalgesia of the same magnitude as that observed after STZ treatment $(21,22)$. However, hyperglycemia may not be the single factor involved in STZ-induced hyperalgesia because insulin treatment did not completely prevent it (23).

Romanosvki et al. (24) demonstrated that, although the intraperitoneal administration of $50 \mathrm{mg} / \mathrm{kg} \mathrm{STZ}$ induced hyperglycemia in $40 \%$ of injected rats, $100 \%$ developed mechanical hyperalgesia. This observation suggests, at least in part, that mechanical hyperalgesia is not completely dependent on STZ-induced hyperglycemia.

The aim of the present study was to design a rational protocol to determine whether systemic administration of non-hyperglycemic doses of STZ induces hind paw mechanical hypernociception in the rat. Additionally, we determined whether the local (intraplantar, ipl) administration of STZ induces mechanical hypernociception.

\section{Material and Methods}

\section{Animals}

Male Wistar rats (180-200 g) were housed in a temperature-controlled room, with free access to water and food. All experiments were conducted in accordance with $\mathrm{NIH}$ guidelines on the welfare of experimental animals and with the approval of the Ethics Committee on the use of animals of the School of Medicine of Ribeirão Preto (University of São Paulo).

\section{STZ treatment}

After $12 \mathrm{~h}$ of food deprivation, rats ( $\mathrm{N}=6-7$ per group) under light anesthesia received citrate buffer (CB; $10 \mathrm{mM}$, $\mathrm{pH} 4.5$; control rats) or STZ (10, 20, or $40 \mathrm{mg} / \mathrm{kg}$; dissolved in $\mathrm{CB}$ ) via the dorsal penile vein. Three days later, glycemia was determined in the morning (8:00-9:00 am) in a blood sample obtained by tail prick using a strip operated reflectance meter (Precision Q.I.D. ${ }^{\circledR}$ Blood glucose Sen- sor; Medisense, Inc., USA). Only rats treated intravenously (iv) with the STZ dose of $40 \mathrm{mg} / \mathrm{kg}$ developed insulin-deficient diabetes characterized by non-fasting blood sugar levels $\geq 250 \mathrm{mg} / \mathrm{dL}$. For the experiments where the local effect of STZ was evaluated, rats $(N=6-7$ per group) received an ip/ injection of $100 \mu \mathrm{L}$ CB or STZ (30, 100 , or $300 \mu \mathrm{g} / \mathrm{paw}$; dissolved in $100 \mu \mathrm{L} \mathrm{CB}$ ). Blood glucose levels were measured $8 \mathrm{~h}$ after ip/ STZ treatment.

\section{Glucose tolerance test}

The test was conducted in the morning 20 days after iv treatment with vehicle (CB) or STZ (10, 20 or $40 \mathrm{mg} / \mathrm{kg}$ ). A blood sample was collected from the capillary bed of the tail tip of rats fasted for $12 \mathrm{~h}$ and the animals then received an iv injection of $0.5 \mathrm{~g} / \mathrm{kg}$ glucose $(1 \mathrm{~mL} / 200 \mathrm{~g}$ body weight). Blood glucose levels were determined again 7.5, 15,30 , and 60 min after the glucose overload as described above.

\section{Nociceptive test: mechanical hypernociception}

Mechanical hypernociception was measured at different times after iv or ip/ injection of STZ using a constant pressure rat-paw test (25). Briefly, a constant pressure of $20 \mathrm{mmHg}$ (measured using a sphygmomanometer) was applied via a syringe piston moved by compressed air to a $15-\mathrm{mm}^{2}$ area on the dorsal surface of the hind paw, and discontinued when the rat presented a typical "freezing reaction". This reaction consists of brief apnea, concomitant with retraction of the head and forepaws, and a reduction in the escape movements that animals normally make to free themselves from the position imposed by the experimental situation. Usually, the apnea is associated with successive waves of muscular tremor. For each animal, the latency to the onset of the freezing reaction was measured before STZ injection (basal latency) and at different times after STZ administration. The intensity of mechanical hypernociception is reported as the reduction in the reaction time, calculated by subtracting the value of measurements after STZ from the basal latencies (25). This mechanical constant pressure test was used in this study because, compared with other mechanical nociceptive paw tests, this test does not present variations in baseline values (typically 32-34 s) and is independent of rat weight. Reaction time was $30.2 \pm 0.5 \mathrm{~s}$ (mean $\pm \mathrm{SEM}, \mathrm{N}=15$ ) before injection of the hypernociceptive agents or after multiple ip/ injections of saline. Mechanical hypernociception was evaluated at indicated times after iv $(10,20$, or 40 $\mathrm{mg} / \mathrm{kg})$ or $\mathrm{ipl}(30,100$, or $300 \mu \mathrm{g} / \mathrm{paw})$ administration of STZ or CB (vehicle, $10 \mathrm{mM}, \mathrm{pH} 4.5$ or 7.0 , respectively). All experiments involving the local administration of STZ and the effect of drugs on the hypernociceptive effect of STZ 
were conducted in a double-blind manner, with the person who injected the solutions (saline, morphine or dexamethasone) being different from the one who made the behavioral assessment.

\section{Paw edema measurement}

Paw edema was measured by volume displacement of an electrolyte solution (7150 plethysmometer, Ugo Basile, Italy) 1,3 , and $5 \mathrm{~h}$ after the $\mathrm{ipl}$ administration of $10 \mathrm{mM} \mathrm{CB}$ $(\mathrm{pH} 7.0,100 \mu \mathrm{L})$ or STZ $(30,100$, or $300 \mu \mathrm{g} / \mathrm{paw}$, in $100 \mu \mathrm{L}$ $\mathrm{CB}, \mathrm{pH}$ 7.0). The increase in paw volume ( $\Delta$ volume) was obtained by subtracting the paw volume measured prior to the injection of the stimuli from the volumes at different times.

\section{Drugs}

The following drugs and reagents were used: streptozotocin and dexamethasone (Sigma, USA), sodium citrate (Merck S.A. Indústrias Farmacêuticas, Brazil), porcine NPH insulin (Biobrás S.A., Brazil), and glucose (Carlo Erba do Brasil S.A., Brazil). Morphine was a gift from Cristália Produtos Químicos Farmacêuticos Ltda., Brazil (lot \#10730/02).

\section{Experimental protocol}

Effects of intravenous injection of STZ on blood glucose, body weight gain, glucose tolerance, and mechanical hypernociception. After $12 \mathrm{~h}$ of food deprivation, rats received an iv injection of $10 \mathrm{mM} \mathrm{CB}$ ( $\mathrm{pH} 4.5$, control rats) or STZ at doses of 10,20 , or $40 \mathrm{mg} / \mathrm{kg}$. Blood glucose levels were evaluated 3 days later and then once a week during the experiment by tail prick using a strip operated reflectance meter (as described above). Body weight and mechanical hypernociception were measured at different times for 36 days after STZ or vehicle treatment (Figures 1 and 2). Mechanical hypernociception and blood glycemia were not assessed on the same day to avoid the effect of acute stress on the mechanical hypernociception measurements. For the glucose tolerance test, additional experimental groups of rats fasted for $12 \mathrm{~h}$ received an iv injection of $10 \mathrm{mM}$ vehicle ( $\mathrm{CB}, \mathrm{pH} 4.5$, equivalent volume) or STZ (10, 20 or 40 mg/kg). Three days later, hyperglycemia was observed only in rats treated with the higher dose of STZ (40 mg/kg). The glucose tolerance test was conducted 20 days after CB or STZ treatment as described above.

Effect of insulin on mechanical hypernociception induced by iv injection of STZ. To test the contribution of hyperglycemia and/or insulinopenia to the genesis and maintenance of mechanical hypernociception induced by iv injection of STZ, rats were treated daily with insulin at doses that completely prevented hyperglycemia. For this purpose, after $12 \mathrm{~h}$ of food deprivation, rats received an iv injection of $10 \mathrm{mM} \mathrm{CB}$ (pH 4.5, control rats) or 10 or $40 \mathrm{mg} /$ $\mathrm{kg} \mathrm{STZ} \mathrm{in} \mathrm{the} \mathrm{morning} \mathrm{(between} \mathrm{8:00-9:00} \mathrm{am).} \mathrm{In} \mathrm{the}$ afternoon of the same day, between 5:00 and 6:00 pm, control rats and STZ-treated rats received a subcutaneous injection of $200 \mu \mathrm{L}$ saline (control groups) or $2 \mathrm{IU}$ insulin (in $200 \mu \mathrm{L}$ ). Insulin or saline was administered twice a day (2 $\mathrm{IU}$ in the morning and $2 \mathrm{IU}$ in the afternoon) 7 days a week for 3 weeks. Glycemia was assessed daily in the morning during the first and second week (except days 7 and 14) to adapt insulin doses. During the third week, the blood glucose measurement was performed in the morning before saline or insulin treatment on a day different day from that of mechanical hypernociception assessment. Mechanical hypernociception was evaluated on days $7,14,16,18$, and 21 after STZ or CB treatment in the afternoon (between 1:00 and 4:00 pm).

Hypernociceptive and edematogenic effects of ipl injection of STZ. This set of experiments investigated the hypernociceptive and edematogenic properties of ip/injection of STZ. Rats received an ip/ injection of $10 \mathrm{mM} \mathrm{CB}(\mathrm{pH}$ 7.0; $100 \mu \mathrm{L})$ or STZ $(30,100$, or $300 \mu \mathrm{g} /$ paw, in $100 \mu \mathrm{L})$ and mechanical hypernociception was evaluated 1, 2, 3, 5, 7, 8, and $24 \mathrm{~h}$ later. In the same rats, paw edema was assessed immediately after the mechanical hypernociception measurements 1,3 , and $5 \mathrm{~h}$ after ip/injection of STZ or CB. Blood glucose levels were measured $8 \mathrm{~h}$ after CB or STZ administration as described above.

Effect of dexamethasone on the mechanical hypernociception and paw edema induced by ipl injection of STZ. Another set of experiments was performed to determine whether the mechanical hypernociception and paw edema induced by local administration of STZ was dependent on the release of inflammatory mediators. Saline (control groups, $0.25 \mathrm{~mL} / 200 \mathrm{~g}, \mathrm{sc}$ ) or dexamethasone $(1 \mathrm{mg} / \mathrm{kg}$, sc) was injected $1 \mathrm{~h}$ prior to STZ $(100 \mu \mathrm{g} / \mathrm{paw}$, in $100 \mu \mathrm{L})$ or CB treatment $(10 \mathrm{mM}, \mathrm{pH} 7.0 ; 100 \mu \mathrm{L})$. The intensity of hypernociception was measured 1,3 , and $5 \mathrm{~h}$ later. The effect of dexamethasone treatment on STZ-induced paw edema was evaluated in the same experimental groups right after the assessment of mechanical hypernociception. Dexamethasone treatment per se did not affect the basal latencies in the mechanical nociceptive test or the paw volume in CB-treated rats (data not shown).

Effect of local or systemic treatment with morphine on mechanical hypernociception induced by iv or ipl injection of STZ. Next, we investigated whether the nociceptive behavior induced by iv or ip/ STZ treatment was inhibited by morphine. In the first experiment, rats fasted for $12 \mathrm{~h}$ received an iv injection of $\mathrm{CB}(10 \mathrm{mM}, \mathrm{pH} 4.5)$ or STZ (10 or $40 \mathrm{mg} / \mathrm{kg}$ ). Three days later, hyperglycemia was confirmed only in rats treated with STZ at the dose of $40 \mathrm{mg} / \mathrm{kg}$. 
As previously observed, iv injection of STZ at doses of 10 or $40 \mathrm{mg} / \mathrm{kg}$ induced a significant mechanical hypernociception 2 weeks after injection (data not shown). The effect of local or systemic treatment with morphine on this process was investigated 31 days after CB or STZ treatment. Briefly, on day 31 the mechanical nociceptive latencies were evaluated before (zero time) and $0.5,1$, and $3 \mathrm{~h}$ after morphine $(8 \mu \mathrm{g} /$ paw or $2 \mathrm{mg} / \mathrm{kg}, \mathrm{sc}$ ) or saline (equivalent volume) treatment. Next, we evaluated the effect of morphine treatment on the mechanical hypernociception induced by ip/ injection of STZ. For this, mechanical hypernociception was evaluated before the treatments (basal latencies) and then saline (equivalent volume) or morphine $(8 \mu \mathrm{g} /$ paw or $2 \mathrm{mg} / \mathrm{kg}, \mathrm{sc}$ ) was administered. Thirty minutes later, rats received an ip/ injection of CB (10 mM, pH 7.0; $100 \mu \mathrm{L})$ or STZ (100 $\mu \mathrm{g} / \mathrm{paw})$. Mechanical hypernociception was assessed again 1, 3, 5 and $7 \mathrm{~h}$ after CB or STZ treatment. In both experiments, morphine treatment did
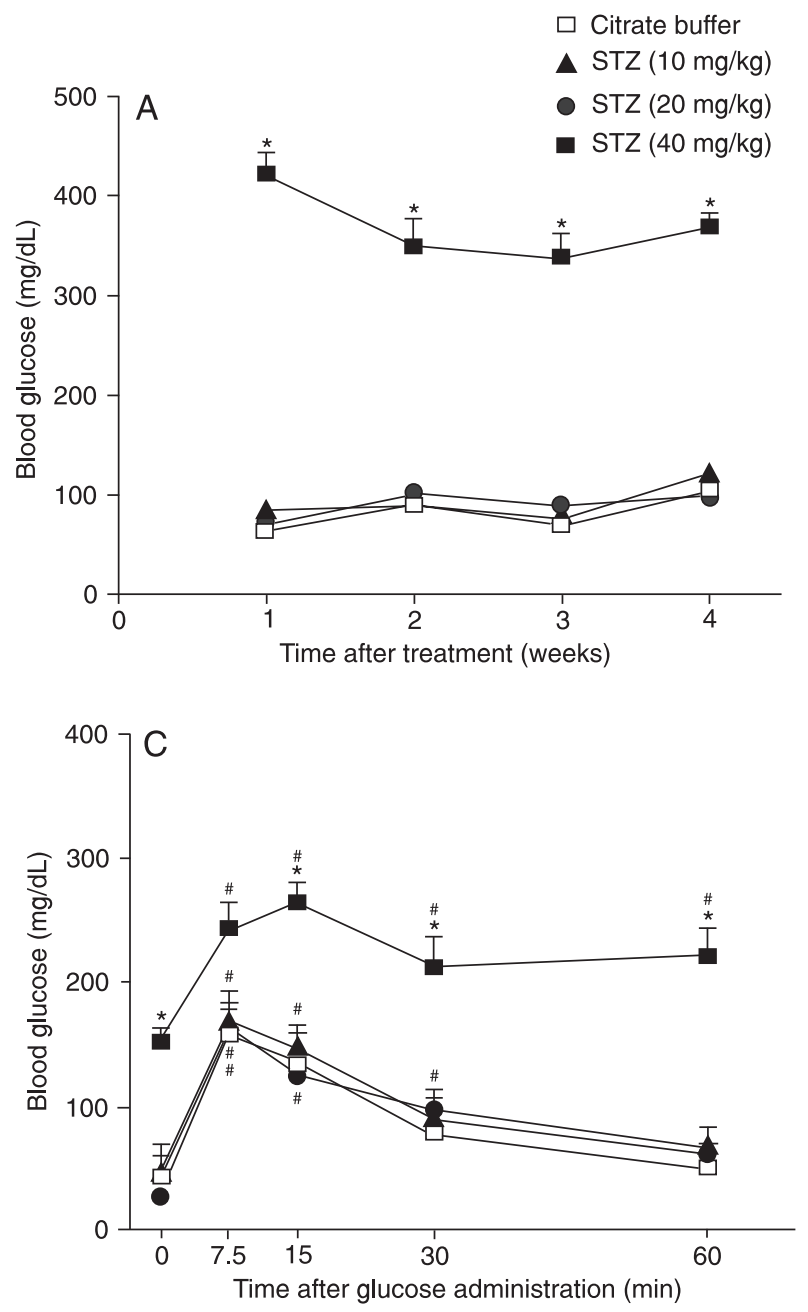

not modify the reaction time in CB-treated control rats (data not shown).

\section{Statistical analysis}

Data are reported as means \pm SEM for groups of 6-7 animals and are representative of two independent experiments. The Student $t$-test for unpaired groups was used, and one-way ANOVA followed by the Bonferroni test was used to determine differences between the experimental groups. A repeated measure ANOVA was used to compare the groups and doses at all times (curves). The level of significance was set at $P<0.05$.

\section{Results}

The data in Figure 1 (panels $A$ and $B$ ) show that iv injection of STZ at doses of 10 or $20 \mathrm{mg} / \mathrm{kg}$ neither induced an increase of blood glycemia nor a loss of body weight

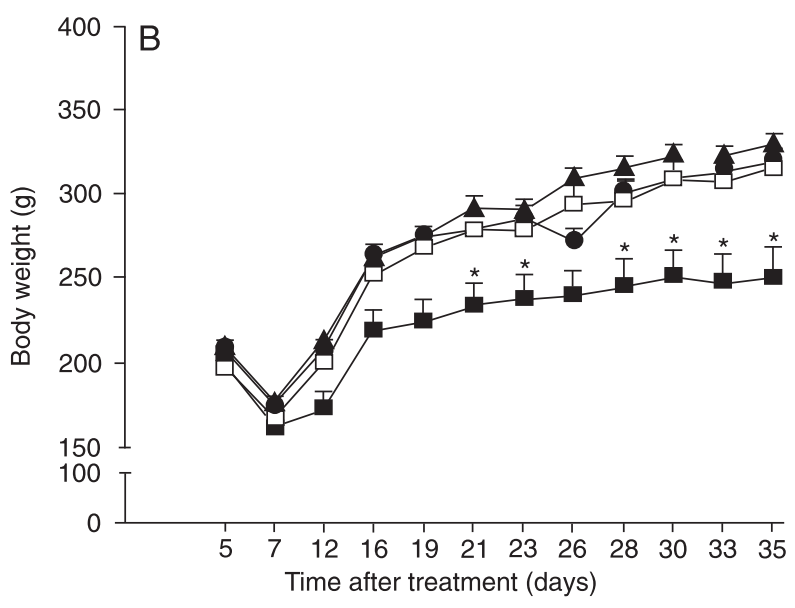

Figure 1. Blood glucose, body weight and glucose tolerance test in streptozotocin (STZ)-treated rats. Rats received an iv injection

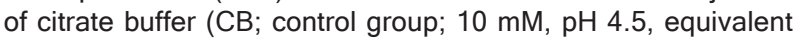
volume) or STZ (10, 20 or $40 \mathrm{mg} / \mathrm{kg}$ ). Metabolic parameters (blood glycemia, panel A and body weight, panel B) were evaluated at the indicated time (weeks or days) after CB or STZ treatments. The glucose tolerance test was performed 20 days after vehicle or STZ treatments (panel C) to determine the time course development of the pre-diabetes state. After $12 \mathrm{~h}$ of food deprivation, blood glucose was measured immediately before iv administration of $0.5 \mathrm{~g} / \mathrm{kg}$ glucose solution (time 0) and then again 7.5, 15, 30, and $60 \mathrm{~min}$ later. Only STZ-treated $(40 \mathrm{mg} / \mathrm{kg})$ rats were glucose tolerant. Data are reported as means \pm SEM for groups of 6-7 rats. ${ }^{*} \mathrm{P}<0.05$ compared to $\mathrm{CB}$ - or STZ- (10 or $20 \mathrm{mg} / \mathrm{kg}$ ) treated rats (ANOVA followed by the Bonferroni $t$-test); \#P $<0.05$ compared to pre-glucose overload levels (panel C). 
compared to CB-treated rats. In contrast, the injection of $40 \mathrm{mg} / \mathrm{kg} \mathrm{STZ}$ induced a significant increase of blood glycemia and a reduced weight gain when compared to citrate buffer-treated control rats $(P<0.05)$.

In the glucose tolerance test (Figure 1, panel C), all rats displayed significantly higher blood glucose levels $7.5 \mathrm{~min}$ after the glucose injection compared to values obtained before the glucose overload $(P<0.05)$. Treatment with STZ at the dose of $40 \mathrm{mg} / \mathrm{kg}$, but not 10 or $20 \mathrm{mg} / \mathrm{kg}$, induced a significant difference in blood glucose uptake after glucose challenge when compared to CB-treated rats. Only the experimental group treated with $40 \mathrm{mg} / \mathrm{kg}$ STZ maintained significantly higher blood glucose levels compared to basal values one hour after the glucose overload (Figure 1, panel C).

Intravenous administration of STZ induced mechanical hypernociception that was independent of hyperglycemia

In addition to the fact that rats treated with $40 \mathrm{mg} / \mathrm{kg}$ STZ displayed hyperglycemia, the $i v$ injection of STZ at all doses used $(10,20$, or $40 \mathrm{mg} / \mathrm{kg})$ induced mechanical hypernociception in the rat hind paw when compared to CB-treated rats $(P<0.05$; Figure 2$)$. The mechanical hypernociception started on day 19 , reached a peak on day 23 and was maintained until day 36 when the experiment was terminated. Intravenous injections of STZ (10, 20 , or $40 \mathrm{mg} / \mathrm{kg}$ ) induced mechanical hypernociception in both hind paws of the same magnitude and with the same time course (data not shown).

Prevention of hyperglycemia by chronic insulin treatment did not inhibit STZ-induced mechanical hypernociception

As shown in Figure 3, daily treatment with insulin, but not saline, completely prevented the development of hyperglycemia induced by iv administration of STZ at the dose of 40 $\mathrm{mg} / \mathrm{kg}$. However, insulin treatment did not alter the course of mechanical hypernociception induced by STZ at doses of either 10 or $40 \mathrm{mg} / \mathrm{kg}$. Additionally, this daily dose of insulin significantly reduced glycemia in normoglycemic experimental groups treated with CB or STZ $(10 \mathrm{mg} / \mathrm{kg})$ during the experimental period (Figure 3 ). Interestingly, in this experiment, mechanical hypernociception developed earlier compared to experiment 1 (Figure 2), i.e., it started on day 14 and reached a peak on day 16 . This discrepancy could be attributed to different potency of the STZ lots.

Mechanical hypernociception and paw edema induced by local administration of STZ

As shown in Figure 4 (panel A), ip/ injection of 30, 100 or $300 \mu \mathrm{g} /$ paw STZ induced ipsilateral mechanical hypernociception in a dose-dependent fashion. The mechanical hypernociception induced by ip/ injection of STZ was statistically significant $1 \mathrm{~h}$ after injection, attained a peak $3 \mathrm{~h}$ later, maintained a significant level until $8 \mathrm{~h}(\mathrm{P}<0.05)$, and was not demonstrable $24 \mathrm{~h}$ post-injection. As expected, none of the ip/ STZ-treated rats displayed a significant increase of blood glucose levels when they were evaluated $8 \mathrm{~h}$ post-injection (means \pm SEM of 6 rats per group, in $\mathrm{mg} / \mathrm{dL}$; CB: $83.60 \pm 2.27 ; 30 \mu \mathrm{g}$ STZ: $89.79 \pm 7.08 ; 100$ $\mu \mathrm{g} \mathrm{STZ:} 89.07 \pm 6.07$ and $300 \mu \mathrm{g}$ STZ: $104.83 \pm 5.67)$. Intraplantar injection of STZ at doses of 100 and $300 \mu \mathrm{g} /$ paw, but not at $30 \mu \mathrm{g} / \mathrm{paw}$, induced a significant increase in paw edema when evaluated 1,3 or $5 \mathrm{~h}$ post-injection (Figure 4, panel B). The increase of paw volume was significantly higher than that observed in CB-treated rats 1 $\mathrm{h}$ after STZ injection, reached a peak at $3 \mathrm{~h}$ and declined thereafter (Figure 4, panel B).

Dexamethasone prevented the edema but not the mechanical hypernociception induced by ipl

administration of STZ

Pre-treatment with dexamethasone $(1 \mathrm{mg} / \mathrm{kg}, s c, 1 \mathrm{~h}$ before STZ) did not alter the nociceptive effect of STZ (100 $\mu \mathrm{g} /$ paw in $100 \mu \mathrm{L}$; Figure 5, panel A). To check the effectiveness of the doses of dexamethasone used in this experiment, paw edema was evaluated in the same ex-

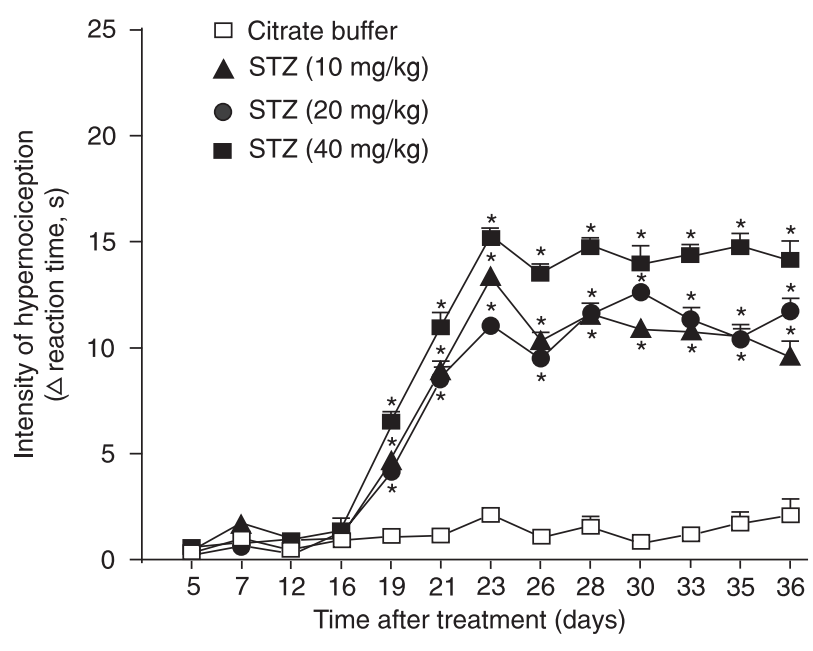

Figure 2. Mechanical hypernociception induced by iv administration of streptozotocin (STZ). Mechanical hypernociception was evaluated on the days indicated after iv administration of vehicle (control group; citrate buffer, $10 \mathrm{mM}, \mathrm{pH} 4.5$, equivalent volume) or STZ $(10,20$ or $40 \mathrm{mg} / \mathrm{kg}$ ). Data are reported as means \pm SEM for groups of 6 rats. ${ }^{*} P<0.05$ compared to citrate buffer-treated rats (ANOVA followed by the Bonferroni $t$-test). 
perimental groups. Intraplantar injection of STZ $(100 \mu \mathrm{g} /$ paw in $100 \mu \mathrm{L}$ ) induced a significant increase of paw volume when compared to CB-treated rats $(P<0.05$, Figure 5 , panel $\mathrm{B}$ ) that was completely prevented by pre-

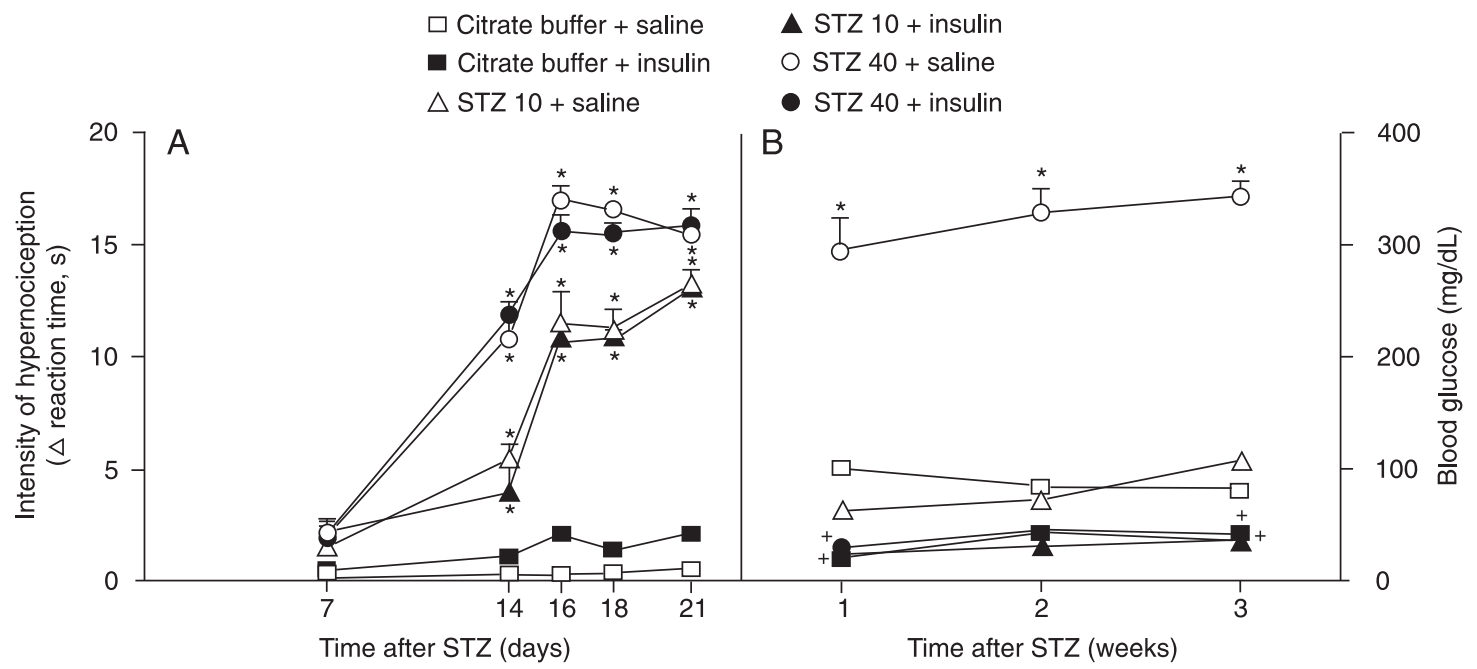

Figure 3. Mechanical hypernociception induced by streptozotocin (STZ) was not prevented by daily insulin treatment. Panel A, Mechanical hypernociception was evaluated on the days indicated after iv administration of vehicle (control group; citrate buffer, 10 $\mathrm{mM}, \mathrm{pH} 4.5$, equivalent volume) or STZ (10 or $40 \mathrm{mg} / \mathrm{kg}$ ). Insulin or saline (equivalent volume) was administered subcutaneously twice (2 IU in the morning between 8:00 and 9:00 am, and $2 \mathrm{IU}$ in the afternoon between 5:00 and 6:00 pm). Panel B, Glycemia was determined in the morning during the $1 \mathrm{st}, 2 \mathrm{nd}$ or $3 \mathrm{rd}$ week after citrate buffer or STZ treatment (10 or $40 \mathrm{mg} / \mathrm{kg}$ ). Data are reported as means \pm SEM for groups of 6 rats. ${ }^{*} P<0.05$ compared to citrate-buffer saline and daily saline-treated rats; ${ }^{+} \mathrm{P}<0.05$ compared to daily saline-treated rats (ANOVA followed by the Bonferroni $t$-test).

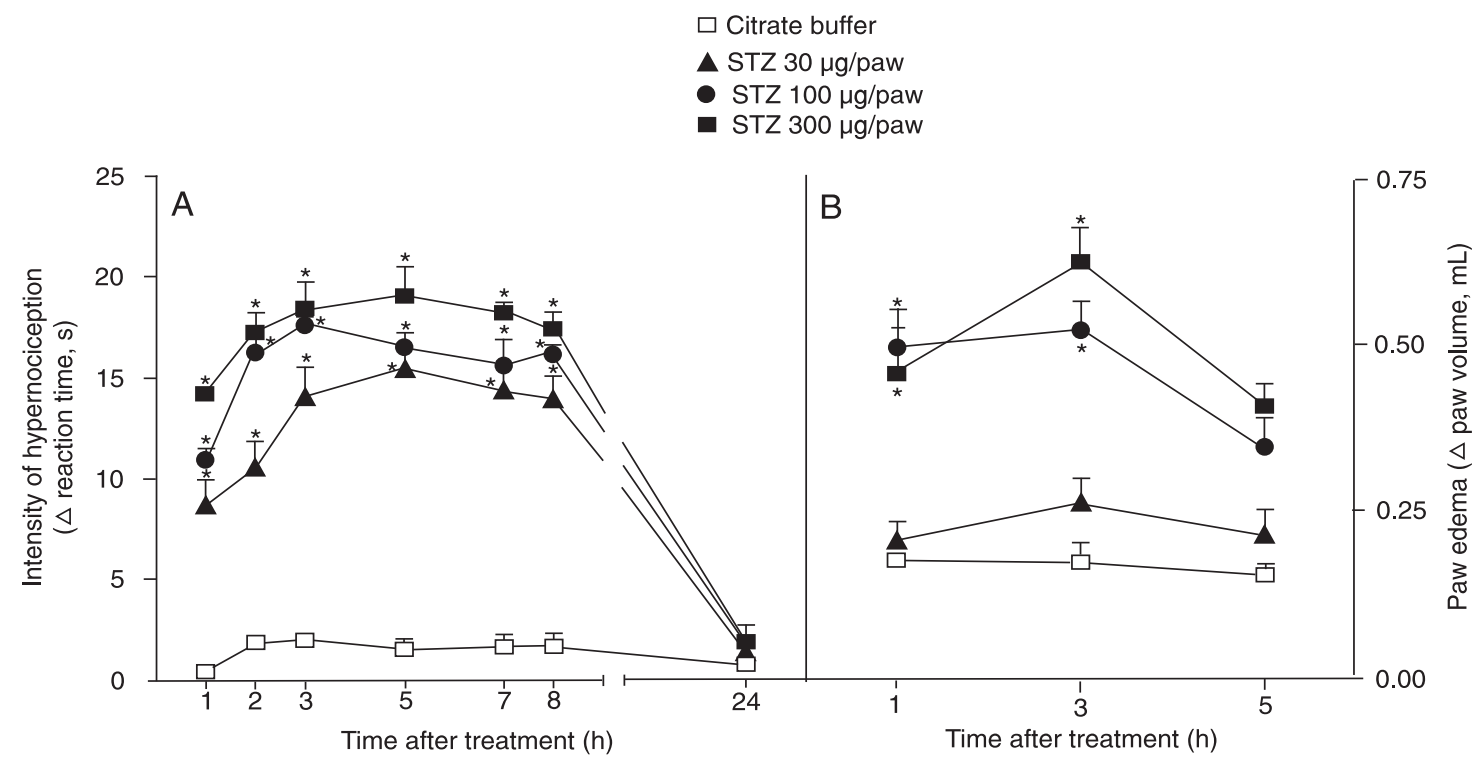

Figure 4. Mechanical hypernociception and paw edema induced by local ipl administration of streptozotocin (STZ). Mechanical hypernociception (panel A) and paw edema (panel B) were evaluated at the indicated hours after ip/ administration of vehicle (control group; citrate buffer, $10 \mathrm{mM}, \mathrm{pH} 7.0 ; 100 \mu \mathrm{L} /$ paw $)$ or STZ $(30,100$, or $300 \mu \mathrm{g} / \mathrm{paw})$. Data are reported as means \pm SEM for groups of 6 rats. ${ }^{*} \mathrm{P}<0.05$ compared to citrate buffer-treated rats (ANOVA followed by the Bonferroni $t$-test). 
treatment with dexamethasone.

Mechanical hypernociception induced by iv or ipl injection of STZ shows different sensitivity to morphine treatment

Morphine (2 mg/kg, sc) administered 31 days after iv
STZ injection or 30 min before ip/ injection of STZ significantly inhibited the mechanical hypernociception induced by all STZ doses (Figure 6 , panels $A$ and $B$ ). In rats treated with iv STZ, the anti-hypernociceptive effect induced by systemic morphine was significant at $0.5 \mathrm{~h}$ and $1 \mathrm{~h}$, returning to the saline control levels $3 \mathrm{~h}$ after injection (Figure 6 ,

- Control

$\square$ Dexamethasone

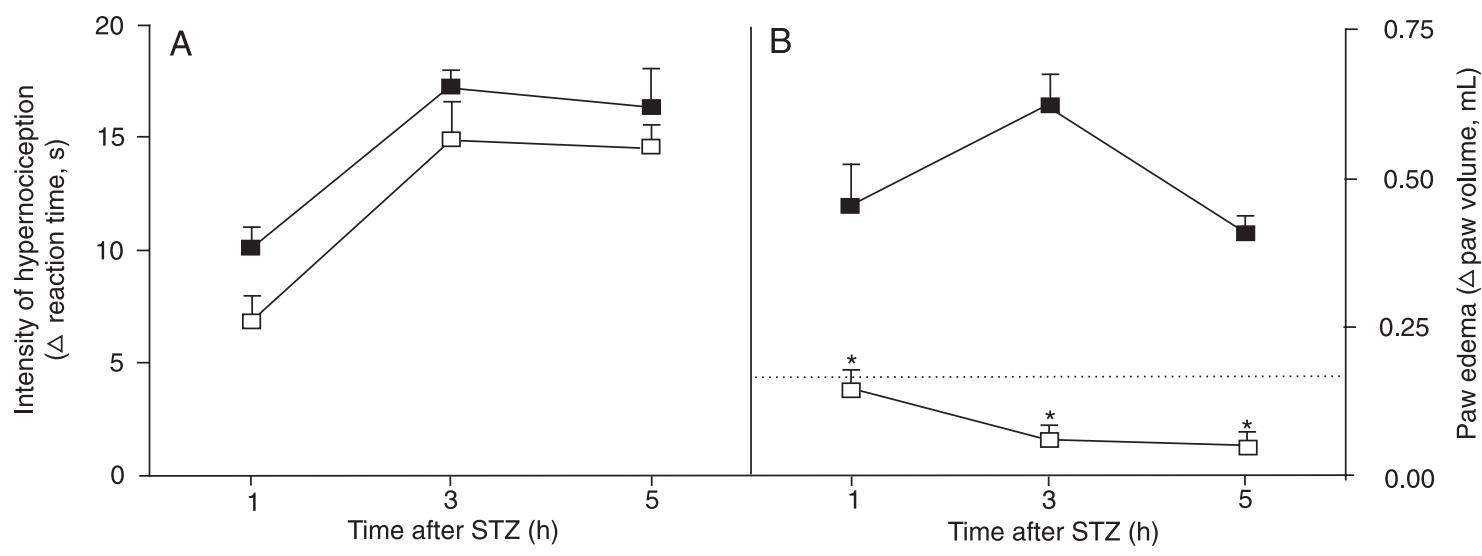

Figure 5. Effect of dexamethasone on hypernociception and edema induced by ipl administration of streptozotocin (STZ). Saline (control groups, $s c ; 0.25 \mathrm{~mL} / 200 \mathrm{~g}$ ) or dexamethasone $(1 \mathrm{mg} / \mathrm{kg}, \mathrm{sc}$ ) was injected one hour before STZ treatment (100 $\mu \mathrm{g} / \mathrm{paw}$ in 100 $\mu \mathrm{L}$ ) and hypernociception (panel A) or edema (panel B) was measured 1, 3 and $5 \mathrm{~h}$ later. The dotted line indicates the paw volume of control rats treated with citrate buffer $(10 \mathrm{mM}, \mathrm{pH} 7.0 ; 100 \mu \mathrm{L} / \mathrm{paw})$. Data are reported as means $\pm \mathrm{SEM}$ for groups of 6 rats. ${ }^{*} \mathrm{P}<0.05$ compared to saline-treated rats (ANOVA followed by the Bonferroni $t$-test).

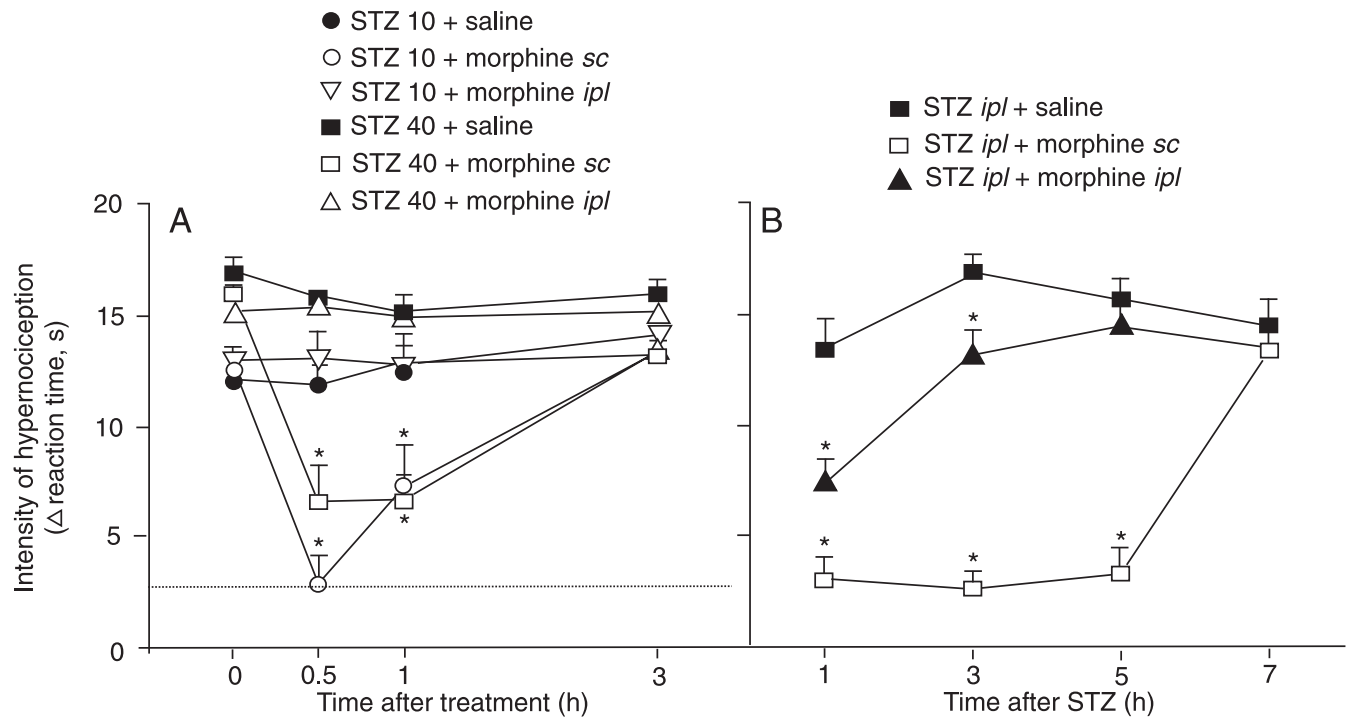

Figure 6. Effect of morphine on mechanical hypernociception induced by streptozotocin (STZ). Panel $A$, Saline (control groups, equivalent volume) or morphine ( $2 \mathrm{mg} / \mathrm{kg}, s c$ or $8 \mu \mathrm{g} / \mathrm{paw}, \mathrm{ipl})$ was injected 31 days after STZ treatment (10 or $40 \mathrm{mg} / \mathrm{kg})$. Mechanical hypernociception was measured before the treatments (time $0 \mathrm{~h}$ ) and $0.5,1$, and $3 \mathrm{~h}$ later. The dotted line indicates the mean reaction time of citrate buffer-treated rats. Panel B, Saline (control group, equivalent volume) or morphine $(2 \mathrm{mg} / \mathrm{kg}, s c ; 8 \mu \mathrm{g} / \mathrm{paw}, \mathrm{ipl}) \mathrm{was}$ injected $30 \mathrm{~min}$ before STZ treatment (100 $\mathrm{\mu g} / \mathrm{paw})$. Mechanical hypernociception was evaluated 1, 3, 5, and $7 \mathrm{~h}$ after STZ injection. Data are reported as means \pm SEM for groups of 6 rats. ${ }^{*} \mathrm{P}<0.05$ compared to saline-treated rats (ANOVA followed by the Bonferroni $t$-test). 
panel A). However, in rats treated with ip/ STZ, the morphine effect remained significantly different from salinetreated rats until $5 \mathrm{~h}$ after $\mathrm{STZ}$ injection $(\mathrm{P}<0.05$; Figure 6 , panel B), returning to saline control levels at $7 \mathrm{~h}$. In contrast, morphine $(8 \mu \mathrm{g} / \mathrm{paw}, \mathrm{ipl})$ significantly inhibited the mechanical hypernociception induced by ipl, but not by iv treatment with STZ (100 $\mathrm{gg} / \mathrm{paw}$ and 10 or $40 \mathrm{mg} / \mathrm{kg}$, respectively; Figure 6 , panels $A$ and $B$ ). The effect of ip/ treatment with morphine on mechanical hypernociception induced by $\mathrm{ip} /$ injection of STZ (100 $\mathrm{gg} / \mathrm{paw})$ was significantly different from saline-treated rats at a time of 1 and 3 $\mathrm{h}$, returning to the saline control levels $5 \mathrm{~h}$ after injection (Figure 6, panel B).

\section{Discussion}

Hypernociception induced by systemic STZ administration has been widely used as an animal model of diabetic neuropathy. It has been demonstrated that STZ induces rapid necrosis of pancreatic $\beta$-cells by activating immune mechanisms, DNA alkylation and/or direct nitric oxide generation $(26,27)$. Fragmentation of nuclear DNA in pancreatic $\beta$-cells is also important for the induction of diabetes (28). Since some rats fail to develop hyperglycemia after systemic administration of STZ, the exclusion of these rats is almost imperative in studies involving hypernociception associated with diabetes. Although this procedure is in accordance with the paradigm of the hypernociception associated with diabetes, the observation that STZ-induced hypernociception in rats is not always associated with hyperglycemia (24) suggests that STZ can induce hypernociception, at least in part, by a mechanism other than hyperglycemia. In fact, in the present study, we demonstrated that systemic, as well as local (ipl) administration of non-hyperglycemic doses of STZ, induces mechanical hypernociception (Figures 2 and 4). In this study, the classical dose of $40 \mathrm{mg} / \mathrm{kg}$ of STZ induced hyperglycemia in all injected rats. In contrast, the doses of 10 or 20 $\mathrm{mg} / \mathrm{kg}$ did not cause hyperglycemia in any of the injected rats (Figure 1, panel A). However, all STZ-challenged rats (hyperglycemic or not) showed a marked decrease in mechanical withdrawal threshold in both hind paws during the two weeks following treatment. In addition, there were no significant differences in time course or magnitude of hypernociception between hyperglycemic and non-hyperglycemic rats (Figure 2). The time course of hypernociception induced by systemic administration of STZ in the present study did not differ from that reported in previous studies (8-15). Our findings suggest that a factor other than hyperglycemia is involved in STZ-induced mechanical hypernociception. Although it has been proposed that the general health deterioration caused by STZ could influence the mechanical nociceptive threshold (29), our study showed that hypernociception induced by STZ was not associated with reduced weight gain (Figure 1, panel B) or general poor health.

It has been proposed that idiopathic sensory neuropathies can be associated with undiagnosed abnormal glucose metabolism and that the steady-state blood glucose concentration is not always a good indicator of diabetic injury (30). To exclude the influence of a pre-diabetes status on the mechanical hypernociception induced by STZ, a glucose tolerance test was performed in all STZtreated rats, but only rats treated with $40 \mathrm{mg} / \mathrm{kg}$ of STZ demonstrated glucose tolerance.

Although our first set of experiments demonstrated that STZ-induced hypernociception was not associated with the impairment of glucose metabolism, it has been suggested that insulinopenia rather than hyperglycemia could be involved in the neuropathy of type 2 diabetes (31). Since normoglycemic STZ-treated rats without glucose tolerance can show a marked reduction in blood serum insulin levels (24), in this study, rats were treated daily with $4 \mathrm{IU}$ insulin. This treatment completely prevented hyperglycemia, but in contrast to previous studies $(6,7,12,20)$ it did not prevent the development of mechanical hypernociception induced by STZ. This incongruent data may be explained by the different experimental protocols adopted or doses utilized.

Taken together, these data strongly suggest that the genesis of the mechanical hypernociception induced by STZ may not be associated only with diabetes. Although the mechanism underlying the STZ-induced mechanical hypernociception remains unclear, we demonstrated in this study that local administration of STZ in the subcutaneous plantar tissue induced mechanical hypernociception in a dose-dependent manner only in the injected paw. However, the time courses of local and systemic administration of STZ were not the same. While systemic STZinduced hypernociception started during the second week and lasted more than 36 days, the hypernociception induced by local administration of STZ was resolved within 24 h. Furthermore, complementary experiments demonstrated that 1) rats treated with an ivinjection of STZ did not display mechanical hypernociception soon after treatment (at 1, 3, 5, 7, or 24 h post-treatment; data not shown) and 2) ip/ injection of STZ did not induce a protracted mechanical hypernociception $(7,14,16$, or 19 days post-treatment; data not shown). It is possible that STZ may differently sensitize the peripheral afferent nociceptors and the central nociceptive neurons, although the hyperglycemia state was not required in either case. In addition, local subcuta- 
neous morphine inhibited the hypernociception induced by local, but not systemic treatment with STZ (Figure 6, panels $A$ and $B$ ). The reduction of the hypernociception mediated by local morphine indicates that STZ may preferentially affect the nociceptors associated with C-fibers given that peripheral opioid receptors are more often expressed in small diameter fibers $(32,33)$. Since small diameter primary afferent fibers are the class of nociceptors predominantly involved in inflammatory pain, it has been plausibly hypothesized that the hypernociception induced by STZ could be dependent on the release of inflammatory mediators. Indeed, local subcutaneous administration of STZ has an edematogenic effect although it was significantly less severe when compared to edema induced by a typical inflammatory stimulus, such as carrageenan.

In the present study, we demonstrated that pre-treatment with dexamethasone completely prevented the STZinduced edema, but did not inhibit the course of mechanical hypernociception. It has been proposed that glucocorticoids such as dexamethasone have an additional biological activity on the phospholipase pathway, i.e., the capacity to stimulate production of inhibitors of kappa $B$, which bind to and inhibit nuclear factor kappa B (NF-кB), a transcription factor that plays a central role in the induction of a number of cytokine genes including tumor necrosis factor $\alpha$ (TNF- $\alpha$ ), interleukin (IL)-1 $\beta$, IL-2, IL-3, IL-6, and IL$8(34,35)$. Several of these genes are also regulated by another transcription factor, activator protein 1 (AP-1) (35), which has a synergistic effect with NF- $\kappa B(36)$. The inhibition of the activities of both NF- $\kappa B$ and $A P-1$ by glucocorticoids provides additional mechanisms to explain the po- tent anti-inflammatory and analgesic effects of these drugs since the role of cytokines in the genesis of inflammatory mechanical hypernociception has been well established (37). Consistent with the role of TNF- $\alpha$ and IL-1 $\beta$ in inflammatory hypernociception, paw skin concentrations of these cytokines increase markedly after injection of carrageenan (38). In neuropathic pain models, IL-1, TNF- $\alpha$ and IL-6 make important contributions to mechanical hypernociception after sciatic nerve constriction (39). However, the plantar cutaneous tissue challenged with STZ, although sensitized to mechanical stimuli, presented a negative immunoreactivity to IL-1 $\beta$, IL-6 or cytokine-induced neutrophil chemoattractant-1 (data not shown).

Indeed, morphine is effective in restoring the reduction of reaction time, which demonstrates a nociceptive character of the behavioral response, as induced by local administration of STZ. However, further studies are needed to better characterize the mechanism by which STZ induces mechanical sensitization of the sensory neurons.

The present data suggest that systemic administration of STZ, a universal chemical agent used to induce experimental diabetes, induces mechanical hypernociception that does not seem to be exclusively dependent on hyperglycemia. This may limit its usefulness as a model of diabetic neuropathy ${ }^{1}$.

\section{Acknowledgments}

The authors gratefully acknowledge the technical assistance of leda R. dos Santos Schivo and Sérgio Roberto Rosa.

\section{References}

1. Veglio M, Sivieri R. Prevalence of neuropathy in IDDM patients in Piemonte, Italy. The Neuropathy Study Group of the Italian Society for the Study of Diabetes, Piemonte Affiliate. Diabetes Care 1993; 16: 456-461.

2. Millan MJ. The induction of pain: an integrative review. Prog Neurobiol 1999; 57: 1-164.

3. Dyck PJ, Zimmerman BR, Vilen TH, Minnerath SR, Karnes $\mathrm{JL}$, Yao JK, et al. Nerve glucose, fructose, sorbitol, myoinositol, and fiber degeneration and regeneration in diabetic neuropathy. N Engl J Med 1988; 319: 542-548.

4. Calcutt NA. Future treatments for diabetic neuropathy: clues from experimental neuropathy. Curr Diab Rep 2002; 2: 482-
488.

5. Forman LJ, Estilow S, Lewis M, Vasilenko P. Streptozocin diabetes alters immunoreactive beta-endorphin levels and pain perception after 8 wk in female rats. Diabetes 1986; 35 : 1309-1313.

6. Lee JH, McCarty R. Glycemic control of pain threshold in diabetic and control rats. Physiol Behav 1990; 47: 225-230.

7. Lee $\mathrm{JH}$, McCarty R. Pain threshold in diabetic rats: effects of good versus poor diabetic control. Pain 1992; 50: 231236.

8. Courteix C, Eschalier A, Lavarenne J. Streptozocin-induced diabetic rats: behavioural evidence for a model of chronic

${ }^{1}$ While this manuscript was being evaluated for publication, Pabbid et al. (2008) published a report (Mol Pharmacol 2008; 73: 995-1004) showing that non-diabetic STZ-treated mice exhibited thermal hind paw hyperalgesia. This study also showed that STZ has a direct action on mouse DRG neurons and modulates the expression and function of TRPV1, a capsaicin-sensitive nociceptive ion channel that is responsible for inflammatory thermal pain. 
pain. Pain 1993; 53: 81-88.

9. Malcangio M, Tomlinson DR. A pharmacologic analysis of mechanical hyperalgesia in streptozotocin/diabetic rats. Pain 1998; 76: 151-157.

10. Wuarin-Bierman L, Zahnd GR, Kaufmann F, Burcklen L, Adler J. Hyperalgesia in spontaneous and experimental animal models of diabetic neuropathy. Diabetologia 1987; 30: 653-658.

11. Courteix C, Bardin M, Chantelauze C, Lavarenne J, Eschalier A. Study of the sensitivity of the diabetes-induced pain model in rats to a range of analgesics. Pain 1994; 57: 153-160.

12. Courteix C, Bardin M, Massol J, Fialip J, Lavarenne J, Eschalier A. Daily insulin treatment relieves long-term hyperalgesia in streptozotocin diabetic rats. Neuroreport 1996; 7: 1922-1924.

13. Calcutt NA, Chaplan SR. Spinal pharmacology of tactile allodynia in diabetic rats. Br J Pharmacol 1997; 122: 14781482.

14. Sasaki T, Yasuda H, Maeda K, Kikkawa R. Hyperalgesia and decreased neuronal nitric oxide synthase in diabetic rats. Neuroreport 1998; 9: 243-247.

15. Khan GM, Chen SR, Pan HL. Role of primary afferent nerves in allodynia caused by diabetic neuropathy in rats. Neuroscience 2002; 114: 291-299.

16. Malmberg AB, Yaksh TL, Calcutt NA. Anti-nociceptive effects of the GM1 ganglioside derivative AGF 44 on the formalin test in normal and streptozotocin-diabetic rats. Neurosci Lett 1993; 161: 45-48.

17. Calcutt NA, Malmberg AB, Yamamoto T, Yaksh TL. Tolrestat treatment prevents modification of the formalin test model of prolonged pain in hyperglycemic rats. Pain 1994; 58: 413-420.

18. Calcutt NA, Li L, Yaksh TL, Malmberg AB. Different effects of two aldose reductase inhibitors on nociception and prostaglandin E. Eur J Pharmacol 1995; 285: 189-197.

19. Calcutt NA, Jorge MC, Yaksh TL, Chaplan SR. Tactile allodynia and formalin hyperalgesia in streptozotocin-diabetic rats: effects of insulin, aldose reductase inhibition and lidocaine. Pain 1996; 68: 293-299.

20. Aley KO, Levine JD. Rapid onset pain induced by intravenous streptozotocin in the rat. J Pain 2001; 2: 146-150.

21. Dobretsov M, Hastings SL, Stimers JR, Zhang JM. Mechanical hyperalgesia in rats with chronic perfusion of lumbar dorsal root ganglion with hyperglycemic solution. J Neurosci Methods 2001; 110: 9-15.

22. Dobretsov M, Hastings SL, Romanovsky D, Stimers JR, Zhang JM. Mechanical hyperalgesia in rat models of systemic and local hyperglycemia. Brain Res 2003; 960: 174183.

23. Gupta M, Singh J, Sood S, Arora B. Mechanism of antinociceptive effect of nimodipine in experimental diabetic neuropathic pain. Methods Find Exp Clin Pharmacol 2003; 25: 4952.

24. Romanovsky D, Hastings SL, Stimers JR, Dobretsov M.
Relevance of hyperglycemia to early mechanical hyperalgesia in streptozotocin-induced diabetes. J Peripher Nerv Syst 2004; 9: 62-69.

25. Ferreira SH, Lorenzetti BB, Correa FM. Central and peripheral antialgesic action of aspirin-like drugs. Eur J Pharmacol 1978; 53: 39-48.

26. Kwon NS, Lee SH, Choi CS, Kho T, Lee HS. Nitric oxide generation from streptozotocin. FASEB J 1994; 8: 529-533.

27. Szkudelski T. The mechanism of alloxan and streptozotocin action in B cells of the rat pancreas. Physiol Res 2001; 50: 537-546.

28. Yamamoto H, Uchigata $\mathrm{Y}$, Okamoto H. Streptozotocin and alloxan induce DNA strand breaks and poly(ADP-ribose) synthetase in pancreatic islets. Nature 1981; 294: 284-286.

29. Fox A, Eastwood C, Gentry C, Manning D, Urban L. Critical evaluation of the streptozotocin model of painful diabetic neuropathy in the rat. Pain 1999; 81: 307-316.

30. Novella SP, Inzucchi SE, Goldstein JM. The frequency of undiagnosed diabetes and impaired glucose tolerance in patients with idiopathic sensory neuropathy. Muscle Nerve 2001; 24: 1229-1231.

31. Murakawa $\mathrm{Y}$, Zhang W, Pierson CR, Brismar T, Ostenson $\mathrm{CG}$, Efendic $\mathrm{S}$, et al. Impaired glucose tolerance and insulinopenia in the GK-rat causes peripheral neuropathy. Diabetes Metab Res Rev 2002; 18: 473-483.

32. Taddese A, Nah SY, McCleskey EW. Selective opioid inhibition of small nociceptive neurons. Science 1995; 270: 1366-1369.

33. Silbert SC, Beacham DW, McCleskey EW. Quantitative single-cell differences in mu-opioid receptor mRNA distinguish myelinated and unmyelinated nociceptors. J Neurosci 2003; 23: 34-42.

34. Scheinman RI, Cogswell PC, Lofquist AK, Baldwin AS Jr. Role of transcriptional activation of I kappa B alpha in mediation of immunosuppression by glucocorticoids. Science 1995; 270: 283-286.

35. Adcock IM, Caramori G. Cross-talk between pro-inflammatory transcription factors and glucocorticoids. Immunol Cell Biol 2001; 79: 376-384.

36. Kovalovsky D, Refojo D, Holsboer F, Arzt E. Molecular mechanisms and Th1/Th2 pathways in corticosteroid regulation of cytokine production. $J$ Neuroimmunol 2000; 109: 23-29.

37. Verri WA Jr, Cunha TM, Parada CA, Poole S, Cunha FQ, Ferreira SH. Hypernociceptive role of cytokines and chemokines: targets for analgesic drug development? Pharmacol Ther 2006; 112: 116-138.

38. Cunha JM, Cunha FQ, Poole S, Ferreira SH. Cytokinemediated inflammatory hyperalgesia limited by interleukin-1 receptor antagonist. Br J Pharmacol 2000; 130: 1418-1424.

39. Milligan ED, Twining C, Chacur M, Biedenkapp J, O'Connor $\mathrm{K}$, Poole S, et al. Spinal glia and proinflammatory cytokines mediate mirror-image neuropathic pain in rats. $J$ Neurosci 2003; 23: 1026-1040. 